\title{
Looking into the Governance of a Public Service Organization in Malta
}

\section{ESJ Social Sciences}

\section{Karen Cacciattolo}

D.Soc.Sci (Leic.), M.Sc. (Trng \& HRM) (Leic.)

University of Malta, Malta

Submitted: 30 July 2020

Accepted: 24 November 2020

Published: 30 November 2020

Corresponding author:

Karen Cacciattolo

DOI: 10.19044/esj.2020.v16n31p19

(c) Copyright 2020 Karen Cacciattolo

Distributed under Creative Commons

BY-NC-ND 4.0

OPEN ACCESS

\begin{abstract}
The study presented in this paper identified the type of synergy and relationship that exists between the employees and other stakeholders of a public service organization in Malta entrusted with cultural and artistic activities. Evidence was gained from indepth interviews and a total of sixty participants took part in the study, which employed a qualitative research design. A methodology based on an inductivist approach was used to explore the participants' experiences, thoughts and opinions. Collected data, which was transcribed and converted to text, was analyzed by using the N-VIVO Qualitative Data Analysis software. In general, the governance as it stands today seems to be 'righteous'. Employees are satisfied with their job and stakeholders are proud to be working for the organization. However, no one knows what the mission statement of the organization is or whether it exists and thus, the mission needs to be clearly and continuously communicated to all. In addition, even though everyone seems to know what the organization stands for, no one knows the exact goals and objectives, and thus, these are required to be rephrased and communicated more to all. With regards to the relationship, synergy and communication between all parties, in general it seems to be good: the weekly meetings between the management and subordinates are of benefit, and there is a cordial relationship between all parties. However, there needs to be more communication with the team of the creative director. Also, more information on the team of the creative director needs to be made visible to the Management Team and the public alike. As regards to the Board of Directors, employees and stakeholders are questioning the
\end{abstract}


suitability and necessity of some of the directors acting in their own capacity since from the study it transpired that they do not seem to be contributing much.
Keywords: Governance, Public Service organization, organizational

communication, Board of Directors

Subject: Business Management

\section{Introduction}

Governance can be assumed to be those processes that are based on the active co-involvement of groups and interests (Cheng, 2019: 192; Vangen et al, 2015: 1244), and the analytical attention of research is often on the forms of relationship among different individuals who go through similar challenges (Nemeth, 2015: 3). According to Garcia \& Cox (2013), governance is one of the dominant areas of discussion, hence its importance for research (2013: 3). Möll and Hitzler (2011) argue that organizations involved in cultural and artistic activities may apply either a pluralist model or a one-tier model, which models are the result of specific theoretical considerations, but have different goals and objectives. In addition, Nemeth (2015) states that most of the literature of the last decade has emphasized the change from municipal focused governance to a more society focused one, in which the network of members is sinuous and casual (2015: 3). This means that the network is developed on the basis that the individuals have to depend on each other, which forces individuals to intermingle and discuss, in order to achieve their personal and mutual goals. As such, in the process, formal and informal rules and relationship patterns are created for future interactions (Cheng, 2019: 192; Nemeth, 2015: 3). Sorensen \& Torfing (2009) postulate that the execution of governance systems in non-profit organizations is subject to the public environment, the strategy of the organization, and the politics that regulate their system and performance (2009: 235). Moreover, Sorensen \& Torfing (2009) assert that it is the responsibility of both the politicians and the civil managers to 'release' the prospect of networks within governance (2009: 235).

According to Sorensen \& Torfing (2009), organizations such as the World Bank, the European Union (EU), multinational corporations, as well as national governments, are inclined to practice and endorse strategic coalitions, partnerships and inter-organizational systems of networks in view of their preemptive and supple style of governance (2009: 236). Similarly, Chen (2019) and Kahler (2015) affirm that governments may choose to negotiate with networks as a new means of collaboration, however this does not mean that there may not be conflicts $(2015: 3 ; 2019$ : 194). There is still the 'knowledge gap', and issues still remain about the difficulty of recruiting people with the right skills (Tonks, 2020: 192), issues with the strength of the team and the relationship management, particularly in creating the right equilibrium between political support and interfering, as well as issues with 
the relationship with the stakeholders (Garcia \& Cox, 2013: 172). Thus, the qualitative research illustrated in this paper took place to address this gap and the subsequent issues mentioned above.

Rotberg (2014) stipulates that most of the work to measure governance has focused on inputs rather than outputs, and this was usually done by assessing the budgets, the financial management style and the indefinable feature of the government (2014: 512). Rotberg (2014) adds that by measuring governance in terms of outcomes, one can determine whether results are being achieved, thus indicating 'good governance' (2014: 517). Sorensen \& Torfing (2009) affirm that the standards summoned by stakeholders in evaluating the effectiveness of particular governance networks can be studied through a qualitative bottom-up analysis based on interviews and documents (2009: 241). As such, the study presented in this paper applied a qualitative method and collected data via in-depth interviews.

The above introduction and literature review illustrated the goals and scope of the research, and explained the broader social context within which the study of governance took place. The introduction makes reference to the academic and other literature about the area of governance in various organizations. This part of the study delineates the contents of the remaining Sections: The methodology section describes how a methodology appropriate to the research was chosen and developed. An in-depth interview guide was designed and used to produce the questions for the data collection for this research. The guide was structured in such a way that the researcher could identify what type of relationship exists between the participants and the organization. The analysis and discussions section follows, which includes analysis and deliberations of the inductively surfaced categories relating to the relationship, synergy and communication between the participants. The categories surfaced from the reading, coding and analysis of the data, and the analysis and discussions are split into the following five main categories, namely the analysis of the organisational model, the effectiveness of internal departments, the stakeholder relationship, the relationship with the board of governors, and the recruitment process. The final section presents the future direction that the research study may take over the years. Changes that might take place in the research process within the foreseeable future are also outlined.

\section{Research Methodology \& Strategy}

The study analyzing the governance of the public service organization in question aimed to explore the relationship between the Management Team, Board of Directors, and various other stakeholders. These relationships are directed by social phenomena and behavioural processes that are accessible through the examination of linguistic and humanistic symbols (Mennell, 1989: 
181). Thus, this study is of a qualitative nature and used an inductivist approach, since it involves obtaining a thorough understanding of social processes and behaviours. The research design took the form of a qualitative case study and the data was collected via a total of sixty in-depth interviews.

The following methodologies were used after defining and selecting a target research population:

a. Obtaining secondary data and/or further documentation - including organizational charts, policies and procedures, and statistics for certain indicators used to formulate the interview guide;

b. Obtaining primary data by organizing and conducting interviews; and

c. Answering the main research questions by assembling, coding and analyzing the replies.

\section{Targeted Participants \& Sampling}

The target participants for this study were involved with and/or linked to the activities carried out by the organization, namely the employees of the Management Team, the Board of Directors, the Creative Director Team, and other persons involved with the organization on an ad hoc basis. All the participants' details were obtained from the Management Team of the same organization and a purposive sampling was conducted. This kind of sampling is planned and aims at setting up a connection between the research questions and sampling (Bryman, 2012: 416).

\section{Data Type, Collection \& Management}

The primary data for this study was collected through the in-depth interviews that took place with the employees of the organization, Directors and other stakeholders. The data collected for this research started by identifying the relevant employees and stakeholders who are involved in the organization's activities. The participants' details were stored in a spreadsheet, to which only the researcher had access. The topics and questions corresponded with the indicators mentioned in the introduction of this paper, and the questions were used in a flexible way (Boeije, 2010: 67). Participants were introduced to the study initially by email and then in person, in the early stages of detecting and building up the target population. Prior permission in writing was sought from the individual that took part in the study before the interview session took place. The participants were all asked to sign a consent form. A total of sixty interviews took place. The researcher took the 'saturation point' approach when interviewing stakeholders, in order to determine the time when no more interviews were required when no new themes were being identified (Bernard \& Ryan, 2010: 71; Boeije, 2010: 84). Even though this approach emerges from a grounded theory perspective, the researcher found it applicable to this study, since the analysis process involved 
a supple and unpredictable coding framework, rather than a firm and unyielding one.

The maximum length of the interviews was of one hour and interviews were recorded, where permitted by the interviewees. Detailed notes were taken during the interviews where audio recording was not the preferred option by the participants. In order to give confidence to participants and persuade them to 'tell their own story', a semi-structured interview approach was considered preferable to a fully structured approach. A phased-assertion probing technique was often used during the interviews. This technique allows the researcher to demonstrate a degree of prior knowledge of their experiences, thus encouraging the interviewees to disclose more information (Bernard \& Ryan, 2010: 33).

$\mathrm{N}-\mathrm{Vivo}$ was used as the data management software. This programme aids in the consistency and regularity of processing the data, and enables the identification, comparison and grouping of common elements in the collected texts by using nodes (Beoije, 2010: 144; Bryman, 2012: 609).

\section{Results \& Analysis}

The framework for analysis of the organization was based on Mintzberg's 'Basic Parts Concept', which includes the following three-level structure, namely (i) analyzing the basic parts of the organization; (ii) analyzing how activities are coordinated and how they are grouped together; and (iii) analyzing the hierarchy: the division of responsibilities \& powers (Shafritz et al, 2015). The organizational chart (Figure 1) was used to structure interviews with the organization's Management Team and Board of Directors. 
ISS: $1857-7881$ (Pint)e- ISSN 1857-7431

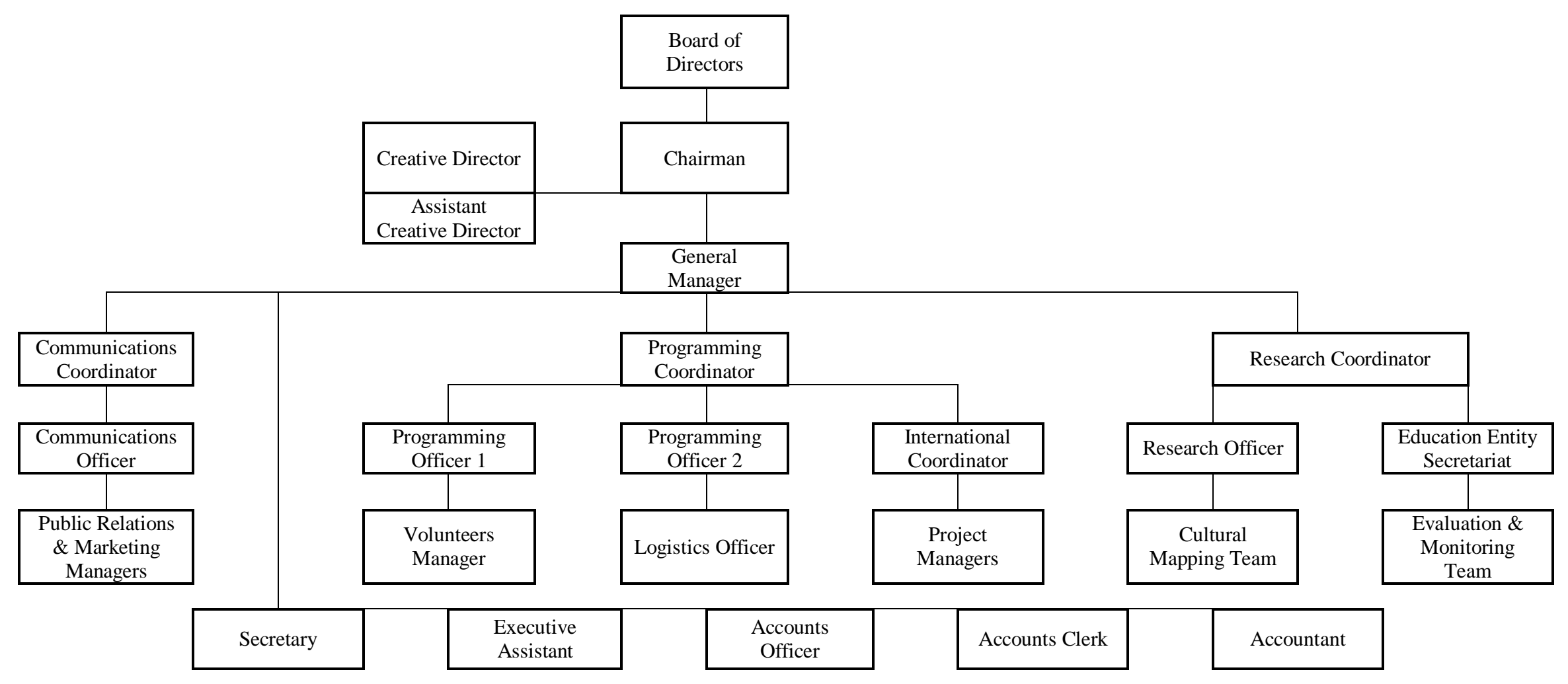

Figure 1: The Organizational Chart 


\section{Basic Parts of the Public Service Organization}

The organization operates through a dominant operating core, whereby staff work rather independently and their relative weight in the organization is visible (Table 1). At the time of this study, the Creative Direction team fell under the Techno Structure area of the organization.

Operating Core: Individuals involved in transforming inputs into outputs.
General Manager;

Coordinator of the Units;

Officers of the Units;

Educational Entity Secretariat;

Assistant Manager;

Secretary, Admin Unit;

Accounts Unit;

Regional Coordinators;

Project Managers, Researchers and other individuals employed

sporadically for specific projects.

Strategic Apex: Individuals entrusted with ensuring that the organization serves its mission by conveying and monitoring the relevant policies and procedures.

Middle Line Management: Individuals involved in joining the Strategic Apex to the Operating Core by feeding information and by coordinating the tasks.

Support Staff: Individuals that are not directly linked to the primary activity, but they provide operational support to this activity.

Techno structure: Individuals involved in the maintenance and development of the efficiency and effectiveness of primary and support activities, including the development, standardization, monitoring and evaluation of events and actions.
Board of Directors;

Chairman;

General Manager.
Coordinators of the Units;

General Manager.
Assistant Manager;

Secretary, Admin Unit;

Accounts Unit;

Educational Entity Secretariat.

Board of Directors;

Evaluation and Monitoring Steering

Committee;

Chairman;

General Manager;

Creative Director;

Vice Creative Director.

\section{Table 1: The Basic Parts of the Organization ${ }^{1}$}

Table 1 illustrates that some individuals carry out activities in more than one basic part: one example is the General Manager, who is involved in all areas except for the Support Staff area. Therefore, based on Mintzberg's concept of Basic Parts, the organization's structure is depicted in Figure 2:

\footnotetext{
${ }^{1}$ Source: Mintzberg, H. (1979), Shafritz, J., et al (2015: 171)
} 


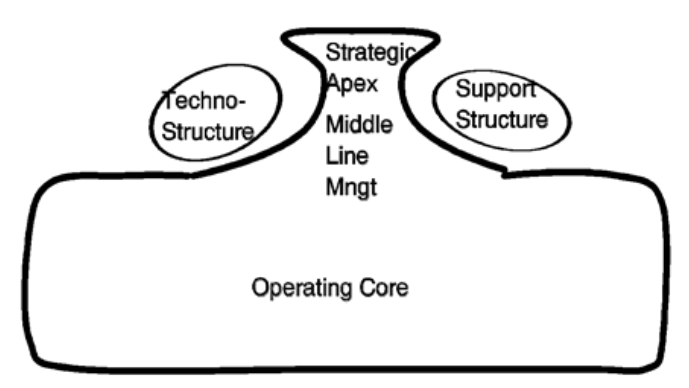

Figure 2: Dominant Operating Core ${ }^{2}$

\section{Coordination of Activities}

Most of the units within the organization consist of a coordinator, who is in charge of the unit, and officers, who respond to the coordinator. Other people engaged on ad hoc basis, such as project managers and researchers, also respond to unit coordinators. All coordinators report directly to the General Manager, who in turn reports to the Chairman. The officers are also encouraged to respond directly to the General Manager where necessary, and sometimes even to the Chairman. From the data it transpired that the General Manager adopts an "open door policy" and is easily accessible to all employees of the Management Team and to other stakeholders. The unit coordinators are a channel of communication between the officers, the people engaged on ad hoc basis, and the General Manager and are responsible to take the necessary decisions within their units. Mintzberg's (1979) 'mutual adjustment' mechanism, which refers to people who depend on each other's work and thus communicate regularly with each other to get the desired results, applies for certain tasks. Therefore, the organization's coordination mechanisms fall between Mintberg's (1979) 'direct supervision', wherein the head of unit coordinates between people directly under his/her responsibility, and 'mutual adjustment', as per Figures 3 and 4.

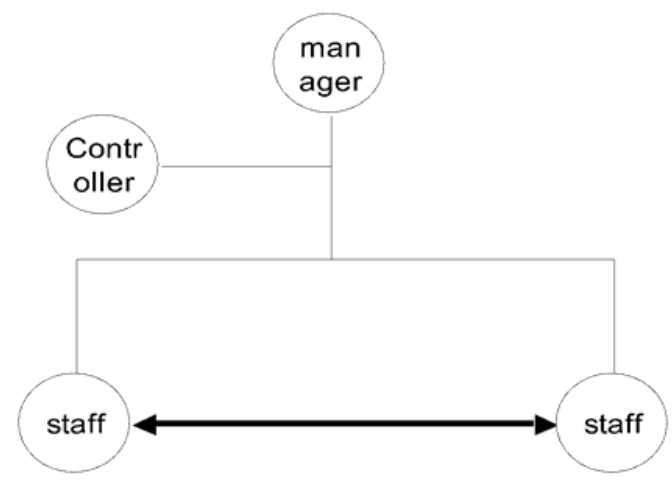

Figure 3: Mutual adjustment mechanism ${ }^{3}$

\footnotetext{
${ }^{2}$ Source: Mintzberg, H. (1979), Hofstede, G. et al (2015)

${ }^{3}$ Source: Mintzberg, H. (1979), Shaftriz, J. et al (2015)
} 


\section{The Organization's Hierarchy: Division of Responsibilities \& Powers}

The organization adopts a traditional hierarchical structure similar to Mintzberg's (1979) 'line organization', which consists of a simple hierarchy with one or more layers of management, with emphasis on direct supervision as per Figure 5.

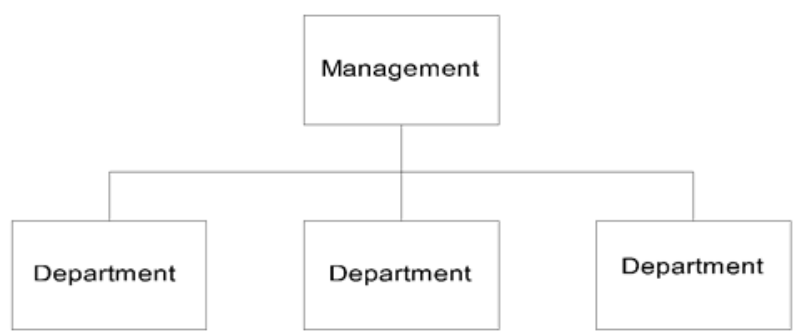

Figure 5: A Line Organization Structure ${ }^{4}$

According to Sahin \& Gozubenli (2014), good governance structure is important for organizations in order for them to be able to jointly make decisions for the benefit of the same organization (2014: 414). Palmer et al (2011) argue that a key governance challenge includes the lack of strength within the team (2011: 27-8) whilst Mohamed et al (2016) stipulate that employees should be held accountable for their actions (2016: 442). Garcia \& Cox (2013) illustrate that some changes in the top level positions of the team may be suitable in order to meet the different demands related to various stages of the activities (2013: 173). The public service organization of the study in question saw one major change after a year of its inception, which is that of the Chairmanship. In addition, its structure had changed, whilst retaining the majority of its staff. The designation of the Project Coordinator was changed to General Manager to reflect a greater responsibility over the projects and the Management Team. Furthermore, two of the coordinators remained on board and their respective units were created. On the other hand, there was a change within the Creative Direction team and its structure.

\section{The Role of the Creative Director}

There are different approaches on how to appoint a Creative Director. In the case of the public service organization in question, the first Creative Director was appointed in Year 1. The Creative Direction team changed and the present Creative Direction team took up the post in Year 3. Interviews reveal that there is still a lack of clarity on the role of the new Creative Direction team. Moreover, the autonomy of the Creative Director at the organization is not without a few challenges, especially with regards to liaising

\footnotetext{
${ }^{4}$ Source: Mintzberg, H. (1979), Shaftriz, J. et al (2015)
} 
with the organization in financial and administrative matters. It is important to note that the office of the Creative Direction team is geographically far from the office of the Management Team. As featured in the organization chart (Figure 1) used for the interviews held, the team of the Creative Director is working rather independently from the rest of the organization's team, in view that they are responsible for different events.

From the data it transpired that the 'distance' creates misunderstandings with regards to communication. Similar to the team of the Creative Director, other employees who are geographically distant from the main premises, or are not always present at the office, in view of their working arrangements or type of employment, feel a sense of discomfort. Similar instances have been observed by Garcia \& Cox (2013) wherein an organization was spatially dispersed over five locations, creating issues with communication, motivation and transparency within management (2013: 177).

\section{Effectiveness of Internal Departments}

Individuals and units behave differently in different situations. The impact that the employees can have on the processes is dependent on their relationship to the organization itself (Friedman \& Miles, 2006; Tonks, 2020: 388-9). Questions for the in-depth interviews in this regard revolved around the mission, goals and objectives of the organization, the forms of synergies between each department and those that are geographically away from the premises, as well as the communication between all parties and any training and development that is required. After all, proper internal management structures, systems and policies enhance the performance of organizations (Kinyua-Njuguna, 2014).

\section{The Mission Statement of the Organisation}

The employees of the Management Team and the Board of Directors of the organisation were asked questions about the mission statement of the organisation, namely whether it is clear and understood by the employees and Directors of the organisation. From the data it transpired that only $46 \%$ are aware that a mission statement exists, though they are not sure of what it states. A few of the Directors commented that the most important factor is that the employees and the Board are aware of what the organisation stands for. The participants who confirmed that a mission statement exists were also asked about the clarity of the said mission statement. Approximately $90 \%$ commented that the mission statement is not clear. 


\section{Goals and Objectives of the Organization}

All employees were asked questions about whether they are aware of the goals and objectives. Though they do not know them word for word, they are aware of what the organization stands for. Participants were also asked to comment about the clarity and transparency of the goals and objectives. The replies were that the goals are either clear or not clear enough. As regards to whether the organization is managing to achieve the results and thus its objectives, such as reaching out to the general public, all employees commented that there is a lot more work that needs to be done in this area. Nemeth (2015) argues that an organization with artistic activities is a prospective opportunity to reach and muster various parts of the society (2015: 5 ), and thus work in this area is of utmost importance.

\section{The Communication, Synergy and Relationship within the Management Team}

The communication effectiveness between colleagues within the units, between the various units, and between the units and thae top management was also discussed with the employees of the Management Team. It transpired that the communication is good across the board. In addition the whole team confirmed that one to one meetings with the General Manager are a normality at the organisation when the need arises. Weekly meetings are also held between the units and the General Manager and a bi-annual meeting is held for the whole team.

Participants within the organization stressed that there is a hefty amount of work to be done, however they feel good and are very content with their job. Albeit the positive feedback provided and listed in the previous sections, a few participants from the Management Team showed concerns on certain managerial ways of doing things, especially in dealing with the media. Participants stated that the management prefers not to deal with such matters. Participants added that perhaps such matters are ignored in view that the management is aware that certain opinionates will never change their way of thinking.

\section{Training \& Development}

All employees were asked whether they feel the need to attend some training programmes that is relevant to their role within the organization. From all the employees, $45 \%$ commented that they require training in various areas. The remaining 55\% of employees commented that they already had some training and also they already had the experience prior to joining the organization and therefore they do not require training at this stage. From the interviews it also transpired that a few employees within the organization are 
pursuing a Master's degree or a $\mathrm{PhD}$, and they are encouraged by the management to enhance their education at their own initiative.

\section{Stakeholder Relationship}

There are formalized governance relationships involving members of the local arts and cultural sector who are an integral part of the processes of the organization. For the purpose of the study in question these members are referred to as the 'stakeholders'. According to Friedman \& Miles (2006) and Tonks (2020), stakeholder management is fundamentally stakeholder relationship management since it is the relationship and not the actual stakeholder groups or individuals that are managed. In addition, Mihanovic, \& Pepur (2015) argue that the organizational effectiveness is increased with the development of adequate organizational and management systems that are orientated towards the stakeholders (2015: 35). The questions formulated revolved around the type and channels of communication, the effectiveness of the organization's efforts to create a good relationship, the efficiency and effectiveness of the Management Team, as well as the advantages and disadvantages of being involved with the organization.

\section{Effectiveness of the Organization to Create a Relationship with the Stakeholders}

All of the participants affirmed that the Management Team is very professional and committed to the goals and objectives of the organization. Many of the participants suggested that the whole process is a learning curve for everyone involved. One of the participants added that the relationship between them was initially uncertain. When participants were asked whether they had experienced conflicts with the Management Team, all of them affirmed that they never really had any serious conflicts, and it is very unlikely that they will ever have, though there were debates on certain aspects of some projects.

\section{General Comments about the Efficiency \& Effectiveness of the Organization}

Participants expressed their concern that the Management Team of the organization may lack the necessary human resources. On the other hand other stakeholders commented that the whole of the Management Team give a lot of importance to their job, and they seem to be working very hard to achieve the organization's goals. It also transpired that various stakeholders like the direction that the Management Team is taking and the way the work is carried out. Various stakeholders added that they perceive the Management Team as a very well organized team even though they do not like the apparent bureaucracy that is involved. Some of the stakeholders suggested that the team 
is required to change its accessibility in order to be more visible and accessible. Moreover, participants from the stakeholders commented that the priorities for organizing events might not be right.

\section{Advantages of Being Involved with the Public Service Organization}

Participants were asked whether they see personal and professional advantages for them to be involved with the organization. The most common advantages are listed in Table 2 below. The list also includes the percentage ${ }^{5}$ of the participants who perceive the advantage:

\begin{tabular}{|l|c|}
\hline Advantage & Percentage of Participants \\
\hline Increase in network & $42 \%$ \\
\hline More exposure & $26 \%$ \\
\hline Enhance my cultural knowledge & $21 \%$ \\
\hline I am given the opportunity to be involved in other projects & $21 \%$ \\
\hline It enhances my experience of working on cultural activities & $16 \%$ \\
\hline It gives more weight to my CV & $16 \%$ \\
\hline
\end{tabular}

Table 2: List of Advantages

\section{Potential Disadvantages of Being Involved with the Organization}

A number of stakeholders showed their concern about being involved with the organization at that moment in time, in view of the political sensitivity of certain individuals. Participants mentioned issues of trying to involve people who support the party that is not presently in government. Other similar concerns include the fear of being associated with one political party and not the other, in view of the organization or individuals being involved with the organization at a time where one political party is in government. Some stakeholders who are concerned about being involved with the organization think that if the organization becomes very controversial and something bad happens, they might be associated with it.

\section{The Interference of Politicians}

A few participants during the in-depth interviews commended that the organization would benefit from some amount of involvement on the part of political leaders. Likewise, literature shows that managers and observers have underlined that there should not be a complete political disengagement (Garcia \& Cox, 2013: 175). Garcia \& Cox (2013) argue that managing the relationship between the politicians and the artistic independence is a key task of organizing an event (2013: 100). In addition, Garcia \& Cox (2013) commented that political leaders may not give attention and importance to cultural subjects, and may be under the perception that culture can happen without

${ }^{5}$ Though the percentages represent the number of participants who mentioned the advantage, one participant may be included in the other percentages in view that he or she has mentioned more than one advantage. 
much dedicated resources or support (Garcia \& Cox, 2013: 175). A few of the participants made similar comments in terms of this perception of political leaders. On the other hand, participants also feel that having politicians intervene in the organisation's processes will hinder the activities and opportunities might be lost. When probed further about similar negative comments such as the above, participants indicated that politicians tend to view culture as something secondary and that it benefits only a minority of the population.

\section{Relationship with the Board}

Until the early 2000s, the governance of organizations did not attract a lot of attention from practitioners and academics, and it was always assumed that what matters most in an organization is the way it is managed (Comforth, 2003: 2). According to Comforth (2003), governance that is problematic stems from the fact that no boundaries are set between the board of an organization and the management of the staff (Comforth, 2003: 127). As such, Tricker (2015) argues that 'governance' has a different meaning than 'management'. Even though usually the board is not featured in an organization chart, and management has been more the focus of how organizations do the business, the board has its due importance. Early in the $21^{\text {st }}$ Century, the importance of good governance started to be recognized (Tricker, 2015: 15). Tricker (2015) and Tonks (2020) argue that governance manages risk whilst creating business value and the whole responsibility ultimately remains with the board (2015: 21, 2020: 44).

This section tackles the analysis of the relationship between the Management Team and the Board of Directors. The questions were formulated from the works of Friedman \& Miles (2006). Questions to analyses the relationship between the Board of Directors and the Management Team revolved around the structure, role and effectiveness of the board, as well the type of communication and relationship that exists between the Directors and the Management Team.

\section{The Structure of the Board}

Initially the Board consisted of six Directors, stemming from other governmental entities including a mayor from a major city. Following the change in the Chairmanship, the Statute was revised to include an additional four Directors from other governmental entities, and three Directors in their personal capacity.

Participants from the Board of Directors and the Management Team were asked questions about their perception on the set-up of the Board. Their comments are in line with the suggestion that the added value of having mayors of the local councils involved may result in increased support and 
interest in a cultural programme (European Parliament 2013: 175). On the other hand, a few of the participants commented that the involvement of the mayor had diminished in view of the fact that the organisation's funding does not come from the mayor's local council, but from Central Government.

\section{The Role of the Board}

Though the Board of Directors is a non-executive Board, it is responsible for setting up the policy direction and supervising the organization's operations. The Board of Directors must review, understand and approve the organization's mission, vision, values and strategic objectives. It must also exercise strict oversight of the organization's programmes and projects to ensure that they are consistent with these documents. It must also ensure that the management is pursuing the mission and vision of the organization and acts in accordance with the organization's values and interests. The Board of Directors must review, understand and approve systems for measuring results, including the organization's social impact and the way that the organization's financial accounts are presented. It is also responsible for approving and checking the implementation of the organization's long-term strategic plans, annual operational plans and yearly budgets. In this regard, the Directors were asked a few questions about their time dedicated to the organization. A few of the participants suggested that if the Directors had sub-committees they would require more time because they would be more involved. Participants understand that the decision of creating sub-committees stands with the Chairman of the organization.

\section{The Effectiveness of the Board of Directors}

When stakeholders were asked about the role and effectiveness of the Board, almost all of them indicated that they have no idea about their input. Despite these concerns, other stakeholders commented that the Directors are not required to actuate anything and that they are there to monitor the organization's process. Participants from the Board of Directors and the Management Team forwarded their own perspective on the Board's effectiveness. These commented that every Board has various types of personalities and there are individuals who are a little laid back, however, on the whole the Board is always forthright. Other participants commented that the Board is not effective. Participants from the Management Team commented that the Directors tend to be more reactive than proactive. One reason provided from the participants is that in view of the Chairman's energetic personality, the Directors tend to take a back seat and leave everything in his hands. Participants added that issues that are supposed to be dealt between one meeting and another are not tended to, and thus much of the work of the organization falls on the Management Team. 


\section{Communication and Relationship with the Management Team}

The Directors were asked to provide feedback on their communication and relationship with the Management Team. In general, the feedback was very positive. Other comments forwarded by the Directors illustrate that there may be lack of communication between the Directors and the Management Team. Reasons put forward by the participants about the lack of communication include that either the Director does not attend the meetings regularly or the information from the Management Team does not reach the Directors in good time.

\section{Recruitment}

As regards to the full-time employees of the organization, an assessment was carried out initially by the researcher to evaluate the following five areas of the organization's recruitment, namely policies and procedures, recruitment strategy, training on recruitment, and the hiring and selection process. The assessment was in line with the work of Portolese Dias (2012) and has been carried out by interviewing the people who are involved and responsible for the recruitment of staff within the organization. Other data was obtained from the organization's documents and government websites.

\section{The Recruitment Policies \& Procedures of the Organization}

The organization's recruitment policies and procedures are in line with the 'Manual of Resourcing Policies and Procedures' of the public service. The organisation thoroughly documents the recruitment, assessment and selection processes, and the policies and procedures are also accessible and understood by the Management Team of the organization and others involved in the hiring process.

\section{Training on Recruitment}

The three members of staff involved in the hiring process had received on the job training on the organization's full recruitment process and thoroughly understand the proper interview and selection techniques. In fact, from the data it transpired that the administrative side of the whole process from shortlisting to issuing the criteria and scores for the interviews - is computed by the administrative staff, which is then double-checked by the General Manager.

\section{The Organsiation's Recruitment Strategy}

The organization has a recruitment strategy in place to meet the needs for the specific positions and the organization's goals, as well as to attract potential applicants. A few employees hail from another government entity, some were employed from the governmental recruitment agency and the rest 
were employed through an open call for applications advertised on the newspaper. All employees are recruited on a definite contract. The chart below represents the organization's recruitment of the Management Team from its first inception. Initially, the organization consisted of three employees; presently it has eighteen, out of which two work on part-time basis. The chart illustrates that there was a hefty increase of $84 \%$ in the number of employees since Year 1.

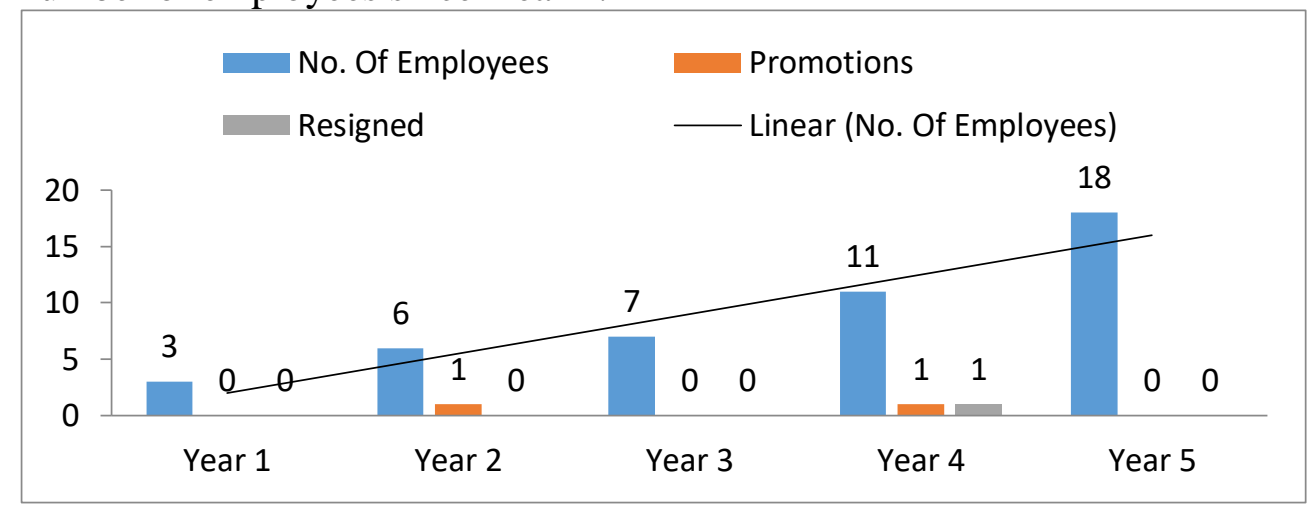

Albeit the increase in the number of employees within the Management Team throughout the years, the data from the in-depth interviews suggests that there is lack of human resources compared with the amount of work involved. A few of the participants have suggested that the organization requires a business development manager on a full-time basis. Others suggested that the employees are not fulfilling their full potential.

\section{The Hiring and Selection Process}

From discussions with the Management Team, it transpired that, over the years from the organization's first inception, the hiring and selection process of the organization ranged between four months to one and a half years to complete, in view of the recruitment procedure which is in line with the Manual on Resourcing Policies and Procedures, wherein the calls are first issued internally for the public officers working within a governmental entity. The manual indicates that if no applications are successful the call is then referred to the governmental recruitment agency, and if still no applicants are successful, the call is advertised on the newspapers. The skills and qualifications required for a post are usually determined by the Chairman and the General Manager. However, at interview stage, the respective Unit Coordinator is usually involved in the selection process. In view that the hiring and selection process is carried out in line with that of the public sector, the interviewing board should always include a high governmental official. The records for the whole process will be kept in line with general Government 
guidelines in view that there might be parliamentary questions during the hosting process and beyond.

\section{Other Expertise \& Support}

The organization also engaged dedicated project managers who are appointed for each activity and event, which, according to Quinn \& O'Halloran (2006), brings experience and knowledge in the area covered by the project. There is also a large number of members who are engaged through a contract for service. These include the team of the Creative Director, and other people in areas such as law, communications, health and safety, information technology, public relations, social media, etc. Apart from providing a picture of what type of human resources the organization is utilizing, one may refer to this section as a thought for the legacy of the expertise that is being utilized for the organization's activities.

\section{Conclusion}

The study examined a number of indicators relating to the discipline of Governance, namely the analysis of organisational models, the effectiveness of internal departments, the stakeholder and Board of Directors' relationship with the organization, and the recruitment process. Overall, the study assessed and provided feedback on all of the above indicators. The study has uncovered the state of governance within the organization.

Following is a summary of the main findings:

$\notin$ The organization adopts a traditional hierarchical structure similar to a 'line organization'. Its structure reflects a dominant operating core, wherein staff in the operating core work rather independently and their relative weight in the organization is visible. The coordination mechanisms fall between 'direct supervision', wherein the head of unit coordinates between people directly under his/her responsibility, and 'mutual adjustment' wherein people between units depend on each other's work;

$\notin$ The organization seems to adopt good governance - Employees are satisfied with their job and other stakeholders are proud to be working for the organization. The relationship, synergy and communication between all parties, seems to be good, though the communication between the Creative Director Team and the Management Team seems to require improvement;

$\notin$ There seems to be lack of knowledge about the mission statement of the organization and the exact goals and objectives seem to be unclear to the participants. Employees and stakeholders alike are also questioning the suitability and necessity of some of the Directors on 
board. Participants expressed the need to have more detailed information about the role of the Board of Directors;

$\notin$ An interest in exchange programmes with foreign artistic organizations has transpired. Similar exchanges have already occurred in the past years, and stakeholders stressed that it would be important and motivating to participate in similar exchanges in the coming years;

$\notin$ The human resources of the organization's Management Team have increased extensively in the last few years from 3 employees in Year 1 to 18 employees by the end of December of Year 5. This indicates a heavy amount of work that is being actuated.

In view of the above findings, it is being suggested that the mission statement, goals and objectives are to be clearly and continuously communicated to all by the top management. The communication with the team of the Creative Director also needs to be enhanced and promoted by the top management. Moreover, more information on the team of the Creative Director is required to be made visible to the Management Team and the public alike.

Whilst all employees and other stakeholders feel proud to be involved in the organization's activities, some expressed concern that the general public might perceive them as being attached to the organization at a particular time in view of the type of government managing the country. Perhaps, more transparency on how people are recruited or engaged with the organization is required to be made available to the general public.

\section{References:}

1. Bernard, H. \& Ryan, G. (2010) Analyzing Qualitative Data, Thousand Oaks: Sage.

2. Boeije, H. (2010) Analysis in Qualitative Research, London: Sage.

3. Bryman, A. (2012) Social research methods, Oxford University Press.

4. Cheng, (Daniel) Y. (2019) Governing Government-Nonprofit Partnerships: Linking Governance Mechanisms to Collaboration Stages, Public Performance \& Management Review, 42(1), pp. 190212.

5. Comforth, C. (Ed.). (2003) The governance of public and non-profit organizations, Routledge.

6. Crosby, Benjamin L. (1992) Stakeholder Analysis: A Vital Tool for Strategic Managers, Technical Notes, No. 2. Implementing Policy Change Project, USAID. Washington, DC.

7. European Parliament (2013) Draft report on the proposal for a decision of the European Parliament and of the Council establishing a Union action for the European Capitals of Culture for the years 2020 
to 2033, COM (2012).

8. Friedman, L. and Miles, S. (2006) Stakeholders Theory and Practice, Oxford University Press.

9. García, B., \& Cox, T. (2013) European Capitals of Culture: Success Strategies and Long-Term Effects, Directorate General For Internal Policies, Policy Department B: Structural and Cohesion Policies. Retrieved

from: http://www.europarl.europa.eu/RegData/etudes/etudes/join/20 13/513985/IPOLCULT_ET\%282013\%29513985_EN.pdf accessed June 2020.

10. Hofstede, G., et al (2015) Cultures and Organizations: Pyramids, Machines, Markets, and Families: Organizing Across Nations. Classics of Organization Theory, 314.

11. Kahler, M. (Ed.) (2015) Networked politics: agency, power, and governance, Cornell University Press.

12. Kinyua-Njuguna, J. W., Munyoki, J., \& Kibera, F. (2014) INFLUENCE OF INTERNAL ORGANIZATION ALENVIRONMENT ON PERFORMANCE OF COMMUNITYBASED HIV AND AIDS ORGANIZATIONS IN NAIROBI COUNTY. European Scientific Journal, ESJ, 10(1). https://doi.org/10.19044/esj.2014.v10n1p\%p, accessed August 2020.

13. Manual on Resourcing Policies and Procedures: https://publicservice.gov.mt/en/Documents/Public\%20Service\%20Ma nagement\%20Code/PSMC\%20Manuals/Manual_on_Resourcing_Pol icies_and_Procedures.PDF accessed June 2020.

14. Mihanovic, Z., \& Pepur, M. (2015) INFLUENCE OF STAKEHOLDER ORIENTATION ON FUNDRAISING OF PUBLIC SERVICE ORGANISATIONS. European Scientific Journal, ESJ, 11(31). Retrieved from http://eujournal.org/index.php/esj/article/view/6597 accessed August 2020.

15. Mintzberg, H. (1979) The structuring of organizations, Englewood Cliffs, NJ: Prentice Hall.

16. Mohamed, A., Youssef, E. W., Malika, S., \& Hafsa, L. (2016) The Ethical Dimension in the New Public Management: Revisiting the Theory of Accountability, the Case of Public Finances in Morocco. European Scientific Journal, ESJ, 12(31), 440. https://doi.org/10.19044/esj.2016.v12n31p440 accessed August 2020.

17. Möll G. \& Hitzler R. (2011) Organisationsprobleme der kulturgetriebenen Transformation moderner Urbanität. Das Beispiel der europäischen Kulturhauptstadt RUHR.2010. In: G. Betz, R. Hitzler, M. Pfadenhauer (editors), Urbane Events, VS Verlag für 
Sozialwissenschaften Wiesbaden, pp. 335-350.

18. Németh, Á. (2015) European Capitals of Culture-Digging Deeper into the Governance of the Mega-Event, Territory, Politics, Governance, DOI: 10.1080/21622671.2014.992804, pp.1-23.

19. Palmer, R. et al (2011) European cultural capital report 3. Association for Tourism and Leisure Education, Arnheim.

20. Portolese Dias, L. (2012) Beginning Management of Human Resources, $\quad \mathrm{http}: / / 2012$ books.lardbucket.org/pdfs/beginningmanagement-of-human-resources.pdf, accessed June 2020.

21. Quinn, B. \& O'Halloran, E. (2006) Cork 2005: An analysis of emerging cultural legacies. Dublin Institute of Technology, http://ECoC-docathens.eu/attachments/998_CORK\%202005\%20AN\%20ANALYSIS\%20OF\%20EMERGING\%20CULTURAL. pdf accessed June 2020.

22. Rotberg, R. I. (2014) Good governance means performance and results, Governance, 27(3), 5p. 511-518.

Sahin, I., \& Gozubenli, M. (2014) CROSS-SECTORAL GOVERNANCE: EXAMINING THE FLORIDA INTEGRATED NETWORK FOR DATA EXCHANGE AND RETRIEVAL (FINDER). European Scientific Journal, ESJ, 10(2). https://doi.org/10.19044/esj.2014.v10n2p\%p accessed August 2020.

23. Shafritz, J., et al (2015) Classics of organization theory, Cengage Learning.

24. Sorensen, E. \& Torfing, J. (2009) Making governance networks effective and democratic through Metagovernance, Public Administration, 87(2), pp.234-258.

25. Tonks, A. (2020) The A to $Z$ of Arts Management: Reflections on Theory and Reality, $2^{\text {nd }}$ Edition, Routledge, New York.

26. Tricker, R. I. (2015) Corporate governance: Principles, policies, and practices, Oxford University Press, USA.

27. Vangen, S., Hayes, J. P., \& Cornforth, C. (2015). Governing crosssector, inter-organizational collaborations. Public Management Review, 17(9), pp. 1237-1260. 